\title{
The Impact of 'Food Addiction’ on Food Policy
}

\author{
Jennifer L. Pomeranz • Christina A. Roberto
}

Published online: 2 March 2014

(C) Springer International Publishing AG 2014

\begin{abstract}
As research on food and addiction evolves, it is important to consider how evidence for the addictive potential of certain foods could change public support for various food policies designed to promote healthier choices. We draw lessons from the framing of addiction in the contexts of tobacco and alcohol to discuss how an addiction frame for food might influence public perceptions and support for specific policies. We then evaluate the regulatory landscape in tobacco and alcohol control to determine which policies may be effective to protect the public against foods that may be harmful. We highlight several viable policy options that could be implemented to protect public health from unhealthy food, even in the absence of a strong scientific foundation that such food is also addictive.
\end{abstract}

Keywords Food addiction · Behavioral addictions · Obesity · Food policy $\cdot$ Public policy

\section{Introduction}

In an effort to gain greater insight into causal and sustaining factors of obesity, the idea that certain food and beverages (collectively food) might be addictive has generated recent scientific inquiry. Although food differs from tobacco and

J. L. Pomeranz $(\bowtie)$

Department of Public Health, College of Health Professionals and Social Work, Center for Obesity Research and Education, Temple University, 3223 N. Broad Street, Suite 175, Philadelphia, PA 19140 , USA

e-mail: jennifer.pomeranz@temple.edu

\section{A. Roberto}

Department of Social \& Behavioral Sciences, Department of Nutrition, Harvard School of Public Health, 677 Huntington Avenue, Rm 617, Boston, MA 02115, USA

e-mail: croberto@hsph.harvard.edu alcohol in many ways, all three of these substances have wreaked havoc on public health [1] and share important similarities [2•]. One key commonality between tobacco and alcohol is that both are considered to be addictive substances. In contrast, it remains an open question whether certain foods trigger an addictive process akin to known addictive substances. The research on food and addiction is too nascent to draw firm conclusions, but the conversation about whether foods can be addictive is starting to permeate both the scientific community $[3 \cdot, 4]$ and the lay public's consciousness $[5$, 6]. The notion that foods can be addictive has been present in popular culture for some time. People often describe food cravings, marketing campaigns use addictive language like the Pringle's slogan "Once you pop you can't stop" or Lay's "Betcha can't eat just one", and self-help treatments for weight loss such as Overeaters Anonymous are predicated on the idea that food can be addictive [7, 8]. A nationally representative survey of American adults also found that $71 \%$ believed that 'food addiction' was an important explanatory factor for obesity; $16 \%$ believed it was "very important" [9].

The goal of this paper is not to make the case that certain foods are or are not addictive, but rather to discuss what the emerging evidence for food addiction might mean for public discourse about poor diet and obesity, and its influence on food-related policy. Using lessons learned from tobacco and alcohol, as well as research on food addiction, we discuss how an addiction frame for food might influence public perceptions and support for specific policies. Depending on the outcome of scientific research linking food and addiction, obesity could be framed as a problem stemming from the overconsumption of certain foods that trigger addictive processes. If this is the case, policymakers might look at previous regulations of tobacco and alcoholic beverages to determine efficacy and legal permissibility of regulating foods that trigger an addictive process. In the second half of the paper, we discuss how strategies used for alcohol and tobacco control 
could be applied to foods demonstrated to be addictive. However, we assert that although the scientific discoveries suggesting certain foods are addictive could strongly influence food policy, such evidence is not required to implement policies that would improve the food environment.

\section{Framing Public Health Policies}

Public opinion and policy can be influenced simply by the way in which a policy is framed [10-12]. In this paper, we use the term framing to refer to making certain aspects of a message salient. Public health problems tend to be viewed from one of two perspectives or frames; first, an individualizing frame that places responsibility for a problem and its maintenance directly on the individual. Those who adopt this kind of frame typically do not support government intervention to address the problem. The second perspective is a systemic frame, which attributes responsibility for the problem to environmental and social forces. This frame lends itself to support of the idea that government has an obligation to intervene to protect the public's health in the face of harmful environmental exposures [13]. Consistent with this, research has found that support for obesity policies increases in America when obesity is attributed to environmental or social forces [14], and it decreases when obesity is viewed as stemming from poor personal choices $[9,15]$. Thus, framing obesity in systemic versus individualizing terms might influence public support for polices such as taxing sugary drinks and placing restrictions on food marketing.

\section{Addiction Frames for Tobacco \& Alcohol}

Alcohol addiction or dependence is currently framed as a disease that people have little control over [16]. Although such a framing might reduce stigma associated with alcoholism, it also de-emphasizes the role that the actual alcoholic product plays in encouraging overconsumption. This reinforces the idea that alcohol only causes a problem for a minority of the population, who struggle with an illness, leading to a treatment focus rather than a prevention focus [16].

The largest step government took to regulate alcohol was through Prohibition in the early part of the twentieth century. Alcohol is still subject to strict government controls beyond concerns over health largely because alcohol use can lead to intoxication, which is associated with accident and crime. Unlike tobacco, alcohol regulation does not hinge on the addictive nature of the product, or on demonizing manufacturers. Similarly, regulation of unhealthy food products does not depend on empirical data pointing to addictive properties of certain foods.

In contrast, smoking has had a different historical framing. In an article examining public discourse about tobacco use,
Nathanson [17•] identifies several effective frames that garnered public support for tobacco policies. One important frame portrayed tobacco's health risk as "acquired deliberately or involuntarily," which removed blame from the individual suffering with the problem. Describing the problem as "knowingly or intentionally created by others" was powerful. The discovery that nicotine was addictive unbeknownst to the consumer suggested there was an involuntary aspect to smoking behavior. It was the knowledge that tobacco companies were misleading the public that helped shift public perception of the companies. This deception, coupled with the tobacco industry's aggressive marketing of an addictive substance, particularly to children, created greater support for tobacco control policies. Another powerful frame portrayed the problem as "universal," meaning that everyone was at risk, not just those choosing to engage in the behavior. A final frame attributed smoking's ill effects to environmental factors, rather than individual behavior. The negative health effects of second-hand smoke supported this frame, as well as the "universal" problem frame, because tobacco was impacting individuals who were not choosing to engage in the harmful behavior. These different frames have led to more aggressive regulation for tobacco, including high taxes and broader restrictions on marketing relative to alcohol.

\section{Food Addiction Frame}

Very little research has been conducted on public perceptions of a food addiction frame. This frame could take one of two forms: addiction to ultra-processed foods could be associated with an increase in obesity for a certain percent of the population who meet criteria for 'food addiction' [18, 19], or certain ingredients (e.g., fructose) might create an addictionlike response in consumers [20]. The first frame is more similar to alcohol framing where people are 'food addicts' who meet diagnostic criteria for food dependence, akin to clinical criteria for alcohol or drug dependence. The latter framing shares greater similarity with tobacco because it focuses on the addictive-potential of certain hyper-palatable foods, rather than the susceptibility of the individual. Thus each frame might lead to differing public perceptions of food addiction and the pursuit of different policy strategies.

In one of the only studies examining public perceptions of food addiction, 570 adults were surveyed and randomly assigned to answer questions about either alcohol, food, or nicotine addiction, and were then presented with a vignette describing an individual addicted to one of the three substances [16]. The study found that food addiction and smoking were more likely to be attributed to free will (personal choice behaviors) than alcoholism. Alcoholism was also more likely to be viewed as a disease rather than a habit, followed by food addiction, and then smoking. People were also more likely to attribute alcoholism to "physical make up" relative to food 
addiction and smoking, but both alcoholism and food addiction were more likely than smoking to be attributed to unhappiness with one's life. The authors conclude that a disease model for food addiction, although not as strong as for alcohol, might be helpful in reducing stigma associated with obesity, but that it could reduce support for the idea that certain foods can trigger addictive processes and should therefore be regulated. At the same time, survey participants felt that food addiction stemmed from personal choice more so than alcohol dependence, which could reduce support for public policy approaches to improve the food environment.

In contrast, if it is discovered that food manufacturers intentionally manipulate food with the goal of eliciting addictive-like responses in consumers, public perception towards the food industry and those products would likely shift considerably, and might place food on a similar trajectory as tobacco control. However, even in the absence of such a discovery, if scientific research establishes that certain food products or properties are addictive, this would likely bolster public support for increased regulation of those foods and make food regulation more politically supportable. In the next section, we discuss various policy options available to regulate food even in the absence of strong science indicating it is addictive. However political support for each strategy differs; the food addiction frame will likely impact support for each policy differently. For example, research found that $63 \%$ of national survey respondents support warning labels indicating that certain foods high in sugar and fat are addictive [9]. A survey of parents revealed they were most likely to support marketing restrictions in schools to protect children; but there was less support for restrictions on specific marketing strategies, such as not allowing child-targeted features on unhealthy food websites, or restricting the use of cartoon characters on packaging (although more than half of parents still supported these measures) [21]. Therefore, the addiction framework could increase support for some of these policy proposals.

\section{Policy Options}

Many government-initiated strategies that were successful for alcohol and tobacco control are directly relevant to the regulation of food. These include tax increases, restricting sale to minors, marketing restrictions, required warning labels and in the case of alcohol, restrictions on retail locations and density within a community. Tobacco control also benefited from government restrictions on smoking in enclosed public spaces [22] and state attorney general (AG)-initiated litigation, both of which set tobacco apart from other products. Further, although additional alcohol control strategies exist, they are likely inapplicable to food or are politically unfeasible, such as prohibiting the operation of a motor vehicle after consuming the product or restricting the days of sale or hours of retailer operation. ${ }^{1}$ In the following section, we discuss the policy options utilized in the tobacco and alcohol fields that are applicable to food. These include food ingredient regulations, age limits, litigation, marketing and labeling restrictions, taxes, and retail restrictions.

\section{Government Authority}

In the USA, the government has a variety of policy options to protect the public from potentially harmful products and minimize costs associated with treating illness that may result from consumption. The Food and Drug Administration (FDA) is responsible for the labeling and safety of food products. State and, to the extent permitted by state law, local governments (collectively states) have the authority to enact laws to protect and promote health, safety, and the general welfare of their population [23]. Product regulation may be directed at all potential users, or to single out minors for specific protection.

\section{Ingredients}

If research reveals that certain ingredients in food can be addictive and cause harm, the most straightforward legal response would be for the FDA to directly regulate the ingredient. Food ingredients are categorized as either "generally recognized as safe" (GRAS) ${ }^{2}$ or "food additives". Examples of GRAS ingredients are sugar, salt and pepper. If an ingredient is considered GRAS, but the evidence reveals that there is no longer a scientific consensus that the ingredient is safe for its intended use, the FDA can initiate proceedings to remove GRAS status and declare the ingredient a food additive. ${ }^{4}$ Unlike GRAS ingredients, food additives are considered unsafe unless the FDA approves their use in food. ${ }^{5}$ The FDA can completely ban an unsafe food additive, an action it is currently undertaking with partially hydrogenated oils (trans fats), or it can proscribe conditions for safe use, which may be more appropriate to address ingredients that are harmful at high levels, such as caffeine [24].

\section{Age Limits}

If science does not support direct regulation of ingredients or it is not politically feasible, government can enact age restrictions for products that have addictive properties. For example, through various legislative mechanisms, Congress has

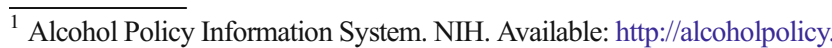
niaaa.nih.gov/

221 CFR 570.30.

${ }^{3} 21$ CFR 570.38

${ }^{4} 21$ USC $\$ 348$.

${ }^{5} 21$ CFR 570.30 .
} 
established a minimum drinking age for alcohol of 21 years old, ${ }^{6}$ and a minimum age to purchase tobacco at 18 years old. ${ }^{7}$ Four states have also increased the tobacco age to 19 [25], and New York City raised it to 21 . In the food context, several state legislators have proposed restricting the sale of energy drinks to minors, ${ }^{8}, 9$ and one county in New York successfully banned the sale of energy drinks to youth under 18 years old in county parks. ${ }^{10}$ If the science supports such action, states would be well within their authority to require a minimum age to purchase addictive and harmful food products.

\section{Litigation}

Perhaps the most well-known use of the law to vindicate public health was litigation by state attorneys general against the major tobacco companies. The attorneys general used their Parens patriae authority, which is available to vindicate the state's interests in the physical and economic health, safety, and welfare of its residents ${ }^{11}$ [26]. The attorneys general initiated such actions based on claims that the tobacco industry's behavior adversely impacted a substantial number of the states' citizens; the states had an independent financial interest in recouping the cost of medical care; and the companies misled the public about the true health risks of smoking [26]. This litigation settled through the Master Settlement Agreement.

The question is whether a similar action would be feasible against food companies that intentionally manipulated ingredients to create an addictive response in consumers. Under that scenario, the industry's actions must cause an injury for which the state could seek retribution. If perhaps, the addictive properties were definitively linked to a certain percentage of obesity or diabetes in the United States, this could provide the basis for such a lawsuit premised on the same rationale as that of the tobacco litigation.

Prior to and since the AG litigation, private plaintiffs have sued the tobacco industry with varying degrees of success [23]. However, lawsuits against companies that produce alcohol, addictive prescription drugs, and food have not been successful and experts believe this is in part due to differing public perception of these products and the companies that produce them [27]. The tobacco companies were vilified after it was discovered that they misled the public regarding the addictive nature of nicotine ${ }^{2}$. Unlike tobacco companies, other industries have not been broadly demonized; in fact some processed food companies are beloved by the public. For example, Coca-Cola has over 79 million fans on Facebook. At this point, litigation based on an addiction argument suffers

\footnotetext{
${ }^{6}$ South Dakota v. Dole, 483 U.S. 203 (1987).

${ }^{7} 21$ CFR 1140.14 .

${ }^{8}$ IL HB 2379 - Prohibition to sell energy drinks to minors (under 18).

${ }^{9}$ ME HB 504 - Prohibit sale of energy drinks to minors.

${ }^{10}$ NY SC Res 1086 - Concerning sale of energy drinks to minors

${ }^{11}$ Maryland v. Louisiana, 451 U.S. 725 (1981).
}

from not enough foundation, but this could change as research into food and addiction evolves.

\section{Marketing and Labeling}

Limiting the advertisement of harmful products is a focus of many public health initiatives. In the USA, the First Amendment of the Constitution protects "commercial speech" from unwarranted government intrusion. ${ }^{12}$ This includes advertising in all types of media, such as television commercials and product packaging. However, the government does have the authority to require companies to disclose factual information or warning statements about their products. ${ }^{13}$ Federal law requires that both tobacco and alcohol product packaging and advertisements bear the Surgeon General's warning. If food additives or products are found to be harmful and addictive, a similar federal warning is conceivable. States may also require warnings for harmful food products when not prohibited by federal law. For example, California law requires companies to disclose that a chemical in products is known to the state to cause cancer, or birth defects or other reproductive harm. ${ }^{14}$ States could consider a similar warning for harmful and addictive food, especially if the federal government does not act.

Currently tobacco marketing is subject to stronger government regulation than alcohol, based on an historical narrative that makes it an unlikely blueprint for other products. The federal government began regulating tobacco advertisements at a time when protecting consumers was politically popular, and before the Supreme Court created the commercial speech doctrine. ${ }^{15}$ Since this time, support for strict controls increased, due to the industry's intentional deception on the health risks of smoking. Further, the tobacco litigation led to the Master Settlement Agreement, under which tobacco companies agreed to further advertising restrictions, such as discontinuing outdoor and transit advertising and ceasing to use cartoons [28]. Alcohol and food have not been subject to similar oversight and government has not attempted to restrict their advertising to the same degree. The Supreme Court has also increased its protection for commercial speech over the last decade and has not upheld a commercial speech restriction since 1995 [29]. At this juncture, the most politically and legally viable initiative to address food marketing would be action directed at protecting children from exposure to ads for harmful products. However, the First Amendment remains a barrier to strong protections, especially when products are legally purchasable by children. Minimum purchase age limits

\footnotetext{
${ }^{12}$ Virginia State Board of Pharmacy v. Virginia Citizens Consumer Council, Inc., 425 U.S. 748 (1975).

${ }^{13}$ Zauderer v. Office of Disciplinary Counsel, 471 U.S. 626, 628 (1985).

${ }^{14}$ Title 27, California Code of Regulations Article 6. § 25601 Clear and Reasonable Warnings.

${ }^{15}$ PBS Frontline. Inside the Tobacco Deal. Full Chronology. http://www. pbs.org/wgbh/pages/frontline/shows/settlement/timelines/fullindex.html
} 
would increase the ability of government to restrict ads directed at them because ads proposing sale to a minor would be for an illegal transaction.

The alcohol and food industry utilize self-regulatory practices ostensibly aimed at protecting youth from inappropriate ads, but critics argue this is actually a method to deflect government regulation ${ }^{2}$. Since 2003, the alcohol industry has voluntarily agreed not to advertise alcoholic beverages on television, radio, or in print media where more than thirty percent of the audience is reasonably expected to be less than 21 years old [30]. The Institute of Medicine and 19 AGs have urged the alcohol industry to shift toward a fifteen percent threshold [30]; the latter noting that the current standard has not led to a decrease in underage drinking [16]. The American Academy Pediatrics Council on Communications and Media advocates a ten percent threshold [31]. The Federal Trade Commission (FTC) conducts studies to determine the extent the industry abides by its commitments [32].

Eighteen food companies engage in self-regulation of food advertisements directed at children, called the Children's Food and Beverage Advertising Initiative (CFBAI). The CFBAI only restricts ads for foods that do not meet a nutritional requirement created by the food industry in media where more than thirty-five percent of the audience is under 12 years old [33]. The FTC studies such marketing but does not specifically determine whether the companies abide by their promises. The FTC found that the food most marketed to youth still includes fast food, sugary beverages, sugary cereals, snacks, and candy [34]. Companies' pledges also do not apply to the retail environment so there is no restriction on the type of marketing directed at children on food packages. Most food directed at children has licensed characters, spokescharacters, bright colors, and games to attract their attention and are also of poor nutritional quality [35]. Therefore, this allowance of on-product marketing undermines whatever efficacy the CFBAI could have once families are in the supermarket.

If research reveals that certain food products are particularly harmful and addictive, increased government regulation to protect children would be warranted. However, at a minimum, self-regulatory efforts should align with that of the alcohol industry, under which products cannot be advertised in media where young people are likely to be in the audience [33]. If there are age limits on the sale of these products to youth, the self-regulatory media age restriction should reflect the sales age restriction. If there is not, there is still a strong argument that youth older than 11 years of age warrant protection from the marketing of unhealthy food, whether or not they are also addictive [36].

\section{Taxes}

Taxation is a method for government to raise revenue and discourage the purchase of unhealthy products through price increases. Both tobacco and alcohol are subject to federal and state excise taxes. Tobacco taxes are credited with a reduction of smoking rates, especially among youth, and reduced youth initiation of smoking [37]. Alcohol taxes are associated with less youth drinking, fewer alcohol-related accidents, and decreased mortality from liver cirrhosis. ${ }^{16}$

Sugary beverages have been the primary target for taxation of food or beverages. Although many jurisdictions have proposed sugary beverage taxes specifically to deter consumption, none of the bills have become law due to strong opposition and industry lobbying [38]. It is likely that support for food taxes could increase dramatically if levied on products established to be addictive and unhealthy.

\section{Retail establishments}

Regulating retail of addictive products can take several forms. Government can regulate both internal business practices and retailer location through direct controls, licensing requirements, and zoning ordinances. States require that tobacco products be placed behind the counter. This can be accomplished through direct regulation or through conditional licensing. Licensing is a method to regulate business practices and define standards of operation. Government can put conditions on retailers' licensing based on their abiding by certain requirements. For example, a retailer's license could be conditional on their locating certain products behind the counter or not giving away free samples.

Government can also regulate retail density through zoning, as is done with alcohol retailers. ${ }^{17}$ However, zoning is generally prospective in nature, so these ordinances only apply to new establishments. Most zoning ordinances are based on rationales such as aesthetics, traffic safety, and pollution, but zoning is a valid method to regulate property to protect public health. ${ }^{18}$ In the food and addiction context, zoning retail outlets would be most applicable if fast food was found to have harmful addictive properties. Jurisdictions currently determine where in the community businesses, including fast food establishments, are permitted to be located; such as away from residential areas, in business districts, or restricted from operating near schools and playgrounds. For example, Detroit prohibits fast food restaurants from operating 500 feet from schools. ${ }^{19}$ Thus, this is a viable policy option whether or not fast food is found to be addictive.

\footnotetext{
${ }^{16}$ The Community Preventive Service Task Force. The Community Guide. Alcohol Taxes. http://www.thecommunityguide.org/alcohol/ increasingtaxes.html

${ }^{17}$ The Community Preventive Service Task Force. The Community Guide. Alcohol. http://www.thecommunityguide.org/alcohol/index.html

${ }^{18}$ Village of Euclid v. Ambler Realty Co., 272 U.S. 365 (1926).

${ }^{19}$ Detroit Zoning Ordinances Sec. 61-12-96; Sec. 61-12-228
} 


\section{Conclusion}

The discovery and framing that certain foods have addictive potential would likely have a strong influence on public opinion about food policies. Policy options that are legally available to regulate food would likely gain greater public support if the products being targeted are found to be addictive. Further, there may be a difference in public support for product properties that create an addictive response and those that are both addictive and harmful. When the addictive property and the harm consequence are features of the same product, strong government regulation is warranted.

Many suggestions in this paper are directly applicable to nutritionally poor food regardless of whether they have addictive properties. Policy options that may be warranted without further evidence for food's addictive potential include age limits on the purchase of particularly harmful products, health warning labels, zoning fast food establishments away from schools, and regulating highly caffeinated food products. If, however, food companies intentionally manipulated products to create an addictive response, this would likely increase support for stricter controls over those food products and the companies that produce them.

Acknowledgments CAR would like to thank the Robert Wood Johnson Foundation Health \& Society Scholars Program for its financial support. The funding source had no role in the preparation, review, or approval of the manuscript.

\section{Compliance with Ethics Guidelines}

Conflict of Interest Jennifer L. Pomeranz and Christina A. Roberto declare that they have no conflict of interest.

Human and Animal Rights and Informed Consent This article does not contain any studies with human or animal subjects performed by any of the authors.

\section{References}

Papers of particular interest, published recently, have been highlighted as:

- Of importance

1. Moodie R, Stuckler D, Monteiro C, Sheron N, Neal B, Thamarangsi T, et al. Profits and pandemics: Prevention of harmful effects of tobacco, alcohol, and ultra-processed food and drink industries. Lancet. 2013;381(9867):670-9.

2. Brownell KD, Warner KE. The perils of ignoring history: Big tobacco played dirty and millions died. How similar is big food? Milbank Q. 2009;87(1):259-94. This reference provides an overview of the many parallels between the tobacco and food industries.

3. Gearhardt AN, Grilo CM, DiLeone RJ, Brownell KD, Potenza MN. Can food be addictive? Public health and policy implications.
Addiction. 2011;106(7):1208-12. This reference discusses the overlap between neural and behavioral responses to food and drugs. The public health and policy implications of the similarities and differences between food and addictive drugs are discussed.

4. Volkow ND, Wang GJ, Tomasi D, Baler RD. The addictive dimensionality of obesity. Biol Psychiatry. 2013;73(9):811-8.

5. Cevallos M. (Apr 2011). If food addiction exists, blame the brain not the cookies. Los Angeles Times. Available at: http://articles. latimes.com/2011/apr/05/news/la-heb-food-addiction-20110405

6. Huget J. (Jan 2011). When food becomes a consuming addiction. The Washington Post. Available at: http://www.washingtonpost. com/wp-dyn/content/article/2011/01/18/AR2011011804857.html

7. Russell-Mayhew S, von Ranson KM, Masson PC. How does overeaters anonymous help its members? A qualitative analysis. Eur Eat Disord Rev. 2010;18(1):33-42.

8. Weiner S. The addiction of overeating: Self-help groups as treatment models. J Clin Psychol. 1998;54(2):163-7.

9. Barry CL, Brescoll VL, Brownell KD, Schlesinger M. Obesity metaphors: How beliefs about the causes of obesity affect support for public policy. Milbank Q. 2009;87(1):7-47.

10. Iyengar S. Is anyone responsible? Chicago: University of Chicago Press; 1991

11. Chong D, Druckman JN. Framing theory. Annu Rev Polit Sci. 2007;10:103-26.

12. Entman RM. Framing: Toward clarification of a fractured paradigm. J Commun. 1993;43(4):51-8.

13. Lawrence RG. Framing obesity: The evolution of news discourse on a public health issue. Int J Press Polit. 2004;9:56-75.

14. Bleich SN, Blendon RJ. In: Public opinion and obesity. Washington, DC: CQ Press; 2010.

15. Oliver JE, Lee T. Public opinion and the politics of obesity in America. J Health Polit Policy Law. 2005;30(5):923-54.

16. DePierre JA, Puhl RM, Luedicke J. Public perceptions of food addiction: A comparison with alcohol and tobacco. J Subst Use. In press.

17. Nathanson C. Social movements as catalysts for policy change: The case of smoking and guns. J Health Polit Policy Law. 1999;24(3): 421-88. This reference provides an analysis of the framing of smoking as a public health problem, how the public viewed it over time, and how that contributed to policy change.

18. Flint AJ, Gearhardt AN, Corbin WR, Brownell KD, Field AE, Rimm EB. Food addiction scale measurement in two cohorts of middle-aged and older women. Am J Clin Nutr. In press.

19. Gearhardt AN, White MA, Masheb RM, Grilo CM. An examination of food addiction in a racially diverse sample of obese patients with binge eating disorder in primary care settings. Compr Psychiatry. 2013;5:500-5.

20. Lustig RH. Fructose: It's "alcohol without the buzz". Adv Nutr. 2013;4(2):226-35.

21. Harris JL, Milici FF, Sarda V, Schwartz MB. Food marketing to children and adolescents: What do parents think? Yale Rudd Center for Food Policy \& Obesity, 2012. Available at: http://www. yaleruddcenter.org/resources/upload/docs/what/reports/Rudd Report_Parents_Survey_Food_Marketing_2012.pdf. Accessed $\overline{4}$ Feb 2014.

22. Wisotzky M, Albuquerque M, Pechacek TF, Park BZ. The national tobacco control program: Focusing on policy to broaden impact. Public Health Rep. 2004;119(3):303.

23. Gostin LO. Public Health Law: Power, Duty, Restraint. 2nd ed. Los Angeles, CA: University of California Press; 2008.

24. Pomeranz J. Legal Implications: Regulating Sales and Marketing. In: Brownell G, editor. Food and Addiction. New York: Oxford University Press; 2012.

25. Centers for Disease Control and Prevention. State laws on tobacco control, 1995. MMWR. Surveillance Summaries. Available at: http://www.cdc.gov/mmwr/preview/mmwrhtml/00039528. htm\#00001355.htm. Accessed 3 Feb 2014. 
26. Ieyoub RP, Eisenberg T. (2000) State Attorney General Actions, the Tobacco Litigation, and the Doctrine of Parens patriae. 74 Tul. L. Rev. 1859.

27. Teret SP, Rutkow L. Legal and Policy Implications: Litigation. In: Brownell G, editor. Food and Addiction. New York: Oxford University Press; 2012.

28. Master Settlement Agreement. Available at: http:// publichealthlawcenter.org/topics/tobacco-control/tobacco-controllitigation/master-settlement-agreement. Accessed 3 February 2014.

29. Pomeranz JL. No need to break new ground: A response to the Supreme Court's threat to overhaul the commercial speech doctrine. Loy. LAL Rev. 2011;45:389.

30. Centers for Disease Control and Prevention. MMWR. Youth Exposure to Alcohol Advertising on Television - 25 Markets, United States, 2010. 2013; 62(44); 877-880. Available at: http:// www.cdc.gov/mmwr/preview/mmwrhtml/mm6244a3.htm

31. American Academy Pediatrics Council on Communications and Media. Policy Statement Children, Adolescents, Substance Abuse, and the Media. Pediatrics. 2010;126:791-9.

32. Federal Trade Commission. (2008) Self-Regulation in the Alcohol Industry. Report of the Federal Trade Commission. June 2008. Available at: http://www.ftc.gov/reports/self-regulation-alcohol- industry-report-federal-trade-commission. Accessed February 3, 2014.

33. Harris JL, Sarda V, Schwartz MB, Brownell KD. Redefining "child-directed advertising" to reduce unhealthy television food advertising. Am J Prev Med. 2013;44(4):358-64.

34. FTC Report. Review of Food Marketing to Children and Adolescents - Follow-Up Report (2009). December 2012. Available at: http://www.ftc.gov/reports/review-food-marketingchildren-adolescents-follow-report. Accessed February 3, 2014.

35. Harris JL, Schwartz MB, Brownell KD. Marketing foods to children and adolescents: Licensed characters and other promotions on packaged foods in the supermarket. Public Health Nutr. 2010;13(3): 409-17.

36. Harris JL, Brownell KD, Bargh JA. The food marketing defense model: Integrating psychological research to protect youth and inform public policy. Soc Issues Policy Rev. 2009;3(1):211-71.

37. Emmons KM, Kawachi I, Barclay G. Tobacco control: A brief review of its history and prospects for the future. Hematol Oncol Clin N Am. 1997;11(2):177-95.

38. Stanford DD. (2012) Anti-Obesity soda tax fails as lobbyists spend millions: retail. Bloomberg Sustainability. Available at: http://www. bloomberg.com/news/2012-03-13/anti-obesity-soda-tax-fails-aslobbyists-spend-millions-retail.html. Accessed Mar 13, 2012. 